\title{
DA ASSEMBLÉIA CONSTITUINTE À CARTA OUTORGADA DE 1824.
}

\author{
NELSON ABEL DE ALMEIDA \\ da Universidade Federal do Espírito Santo.
}

Neste ano de 1972, em todos os rincões deste país, tem se dado ênfase aos cento e cinquenta anos de sua vida independente, com pronunciamentos e manifestações de todas as classes sociais, aliados a estudos alentados de intelectuais, e de instituições culturais, sobre o episódio magno da nacionalidade.

$E$ isso vem sendo cuidadosamente feito, desde ha um ano passado, quando Portugal concordou em confiar, ao Brasil, para todo o sempre, a guarda dos despojos de Pedro I, Imperador brasileiro e Rei Português que, em seu tempo, soube viver toda a realidade e todos os sonhos das duas Pátrias.

Agora, e era natural que assim acontecesse, a Ordem dos Advogados do Brasil, por determinação do seu Egrégio Conselho Federal, vem de encarecer, às Seccionais, nos Estados, que promovam sessões solenes, ao ensejo do acontecimento impar, que foi a Independência do Brasil e que é o transcurso do seu Sesquicentenário, a fim de que fique marcada a presença e a participação do advogado brasileiro nas festividades que se vem processando na Terra de Santa Cruz.

Aqui no Espírito Santo, também uma solenidade se está realizando agora. Convocado, para dela participar, venho me desincumbir do chamamento, com a certeza de que estou sendo exaltado e dignificado pelo encargo que me foi atribuido, e também tendo a consciência de que outros, nos quadros da Ordem dos Advogados do Brasil, na Seç̧ão do Espírito Santo, ilustrariam melhor que eu esta solenidade.

Nestes quatrocentos e setenta e dois anos de vida civilizada do Brasil, muito se tem estudado a nossa história e muito se tem escrito sobre o povo brasileiro, o que tem sido feito até por estudiosos alienígenas. 
Já em 1899 Vacher de Lapuge, em um livro, célebre em seu tempo - L'Aryen - teria descrito o Brasil como "un immense Etat négre qui, retourne à la barbarie", acrecentando que, semelhantemente ao México, a sua importância é "somente numérica".

Um outro escritor - Chamberlain - em La Genèse du XIX siècle, admite que "a América do Sul oferece nos seus Estados mestiços, o mais lamentável espetáculo. Para ele, os selvagens da Austrália Central levam uma existência muito mais harmoniosa, mais digna de creaturas humanas, mais sagrada que "esses infelizes Peruanos, Paraguaios, etc.", nascidos de uma união ilegítima entre duas e, as vezes, mais raças inassociáveis, entre duas culturas que nada tem de comum, entre dois estados de desenvolvimento muito diversos, na forma e na idade, para se casarem, produto de um atentado contra a natureza".

Para Chamberlain, entretanto, o Brasil "português" é uma exceção, visto como aqui "as circunstâncias são essencialmente diversas".

Sim, aqui, "as circunstâncias são essencialmente diversas"; aqui, nesta natureza marcadamente tropical, o branco (português), o negro e o indígena já se haviam caldeado e, unidos, cuidaram de extravasar todo o seu sentimento nacional, todo o seu devotamento à terra moça da América, na reconquista de todo o Nordeste, e de parte de outras regiões, ao invasor holandês.

Franceses no Rio de Janeiro e no Maranhão, ingleses em Santos, em Vitória e em Pernambuco, holandeses na Bahia e em Recife, na Paraíba e no Rio Grande do Norte, como em outros pontos do nosso litoral, com a sua audácia e o seu destemor, com a sua ambição e o seu heroismo foram, inegàvelmente, motivação no amálgama da nova nacionalidade que aqui, do outro lado do Atlântico, dia a dia, mês a mês, ano a ano, se formou para orgulho e envaidecimento nosso.

A Insurreição Pernambucana, quando das Invasões Holandesas, a República dos Palmares em Alagoas, a Revolta de Filipe dos Santos nas Minas Gerais, as Guerras dos Emboabas e Mascates, a Inconfidência Mineira comandada pelo bravo e intrépido Tiradentes, a Revolução de 1817, e quantas outras contestações do Brasil Colônia, são os alicerces que forjam a nacionalidade brasileira e os marcos que assinalam a caminhada para o Sete de Setembro.

A Revolução Brasileira de Pedro I, como bem conceituou Brasil Gerson, o ato que, em definitivo, separou o Brasil de Portugal, não é um ato isolado e solitário, no contexto histórico do século passado. E fazer a Independência do Brasil, declarar a sua separação de Portugal não era tudo, visto como necessário se tornaria organizar, jurídica e 
constitucionalmente, a nação que, de então para diante, iria responder pelo seu destino e forjar o seu futuro.

Esta a responsabilidade, de ampla envergadura e magnitude, que passou a pesar sobre os ombros dos artífices do Sete de Setembro de 1822, após aquele epsodio que se passara às margens do riacho Ipiranga, às vizinhanças da velha e colonial cidade de São Paulo.

E desta tarefa hercúlea e ingente, ninguem tenha dúvida, dentro dos princípios que defendiam e das rivalidades que surgiam, os Andradas, Gonçalves Ledo, Januário da Cunha Barbosa, José Clemente Pereira, Cairú, Cipriano Barata, Feijó, e quantos e quantos outros, só viam um ideal - fazer do Brasil uma nação livre e respeitada.

Difícil, entretanto, era a tarefa a ser executada e realizada, eis que a terra estava do lado de cá, em outro hemisfério e, que se não esqueça, era habitada por um povo que tinha, da organização política $e$ social de uma nação, um conceito que estava longe de ser o vigente em Portugal e na velha Europa.

Ainda, aqueles homens, representantes de uma elite brasileira, tinham formado a sua cultura e a sua consciência jurídica em Coimbra, em Paris e em outras Universidades européias. Agora, sentiam todos que a terra nova e o povo jovem deveriam ter leis que se coadunassem com a nacionalidade que começava a se afirmar.

Viam todos, e dentre este se incluia o Príncipe Regente D. Pedro, ser necessário um estatuto constitucional para o Reino do Brasil e, por sentir a necessidade da organização jurídica da nova nacionalidade, convocou D. Pedro, em 3 de junho de 1822, antes da proclamação da Independência,

$$
\begin{aligned}
& \text { "uma assembléia geral constituinte e legislativa, composta de } \\
& \text { deputados das provincias do Brasil". }
\end{aligned}
$$

E decretada esta convocação, no dia 19 do mesmo mês José Bonifácio, que era Ministro, interpretando os sentimentos do Conselho dos Procuradores Gerais das Províncias, órgão liderado por Gonçalves Ledo, expede as instruções que iriam regular a sistemática da eleição dos deputados.

Face às instruções baixadas,

"os solteiros maiores de vinte anos e todos os casados fariam a escolha (no $1^{\circ}$ círculo) dos eleitores da paróquia, e este por sua vez, nas cabeças de distrito, completariam o processo, devendo-se, porém, salientar que no $1^{\text {o }}$ círculo a participação do eleitorado 
era a mais ampla, com a inclusão, nela, dos analfabetos e dos que não dispunham de renda, e a exclusão tão sòmente dos componentes das ordens religiosas, dos filho família, dos que recebessem salários ou soldados, e dos estrangeiros não naturalizados e dos criminosos. Quanto às apurações, seriam elas procedidas pelas Câmaras Municipais, e as finais da Província pelas Câmaras de suas capitais".

Enquanto isso, no Rio de Janeiro,

"a eleição dos cariocas e fluminenses se realizaria no Mosteiro de São Bento, sob a presidência de José Clemente Pereira, saindo depois todos juntos, os eleitos e os eleitores, em procissão pela cidade, à frente de uma banda militar e o estandarte do Senado da Câmara, aplaudidos pelo povo - e com Te Deum na Capela Real, festas no largo do Rocio e sessão à noite no Teatro, com a presença de D. Pedro e D. Leopoldina e dando-se já, nos vivas da multidão, a sua elevação, de Principe Regente, a Imperador do Brasil".

Assim, teriam sido eleitos noventa deputados, representando as diversas províncias - vinte por Minas Gerais, treze por Pernambuco, onze pela Bahia, nove por São Paulo, oito pelo Rio de Janeiro, incluida a cidade do Rio, oito pelo Ceará, cinco pela Paraíba, cinco por Alagoas, quatro pelo Rio Grande do Sul, dois pelo Rio Grande do Norte, dois por Goiás, um pelo Espírito Santo, um por Mato Grosso e um por Santa Catarina.

Não foram relacionadas as Províncias do Pará e do Maranhão, ainda não integradas, de todo, no Império, como também o Amazonas, Paraná e Sergipe, que não apareciam ainda como Províncias, também não foram incluidas na relação.

Embora convocada em 3 de junho de 1822, só em 3 de maio de 1823 seria a Assembléia Constituinte instalada no edifício da Cadeia, que fora reformado e ampliado, o que determinou passasse a rua da Cadeia a ser conhecida, daí por diante, como rua da Assembléia.

Possivelmente, ao Deputado Gonçalves Gomide, representante de Minas Gerais, cabe a responsabilidade pelo fato de ter sido instalada, em 3 de maio de 1823, a Assembléia Constituinte, no Império, visto como, em 12 de abril daquele ano, escreveu ele, ao Ministro do Império e Estrangeiros, carta a respeito, que é do teor seguinte: -

"Conversando com o Conselheiro Diogo de Toledo me ocorreu uma idéia, que ele insinuava propuzesse a V. Excia. Lembrei 
que o dia mais adequado para a instalação das Cortes era o dia 3 de maio, motivada esta eleição em ser o Descobrimento do Brasil, na relação que tem com o Cruzeiro Austral, e com a bem lembrada Ordem do Cruzeiro Imperial, não sendo indiferente que na descoberta da terra por um Pedro outro, no mesmo dia, lançasse a primeira pedra no edifício eterno da nossa Constituição".

$\mathrm{E}$, no dia 3 de maio de 1823 , seria solenemente instalada, às doze e meia horas, sob a presidência do Bispo do Rio de Janeiro - D. José Caetano da Silva Coutinho - a primeira Assembléia Constituinte Brasileira, estando o seu plenário literalmente repleto, presente o Imperador Pedro I, que leu a primeira Fala do Trono, com a qual surpreendeu os representantes do povo brasileiro, Fala do Trono esta, assim iniciada:

"É hoje o dia maior, que o Brasil tem tido; dia em que ele pela primeira vez começa a mostrar ao mundo, que é Império e Império livre. Quão grande é meu prazer vendo juntos representantes de quase todas as províncias fazerem conhecer umas às outras seus interesses, e sobre eles basearem uma justa e liberal constituição que as reja".

Vê-se, aqui, nesse passo da Fala do Trono que, também o coração do primeiro Pedro vibrou, de entusiasmo e de ufania, por um Brasil uno, indivisivel de norte a sul e de leste a oeste.

Mas, na mesma Fala do Trono, o nosso jovem Imperador, figura histórica bem incompreendida, de atitudes paradoxais, que causam pasmo aos que se debruçam sobre a sua vida de fundador de nacionalidades, acentua:

"Afinal raiou o grande dia para este vasto Império, que fará epoca na sua história. Está junta a assembléia para constituir a nação. Que prazer! Que fortuna para todos nós!

Como Imperador Constitucional, e mui especialmente como defensor perpétuo deste Império, disse ao povo no dia $1^{\circ}$ de dezembro do ano próximo passado, em que fui coroado e grado, que com a minha espada defenderia a pátria, a nação e a constituição se fosse digna do Brasil e de mim".

Veio a frase ambígua, chocante, para perturbar aquela sintonia de ideais e aquele universo de entusiasmos provocados pela proclamação da Independência. E já no dia 6 de maio, o deputado Luiz Inácio de Andrade e Lima mostra, à Assembléia Constituinte, que 
“a Fala de Sua Majestade Imperial está sem dúvida concebida em termos constitucionais, mas nota-se no fim dela algumas palavras ambíguas, cujo sentido não é bem claro. Diz que espera que a Assembléia faça uma Constituição digna dele $\mathrm{c}$ do Brasil e que, sendo assim a defenderá; ora, constituindo-se desse modo Juiz em causa própria, e sendo ao mesmo tempo defensor do Brasil, poderá inferir-se que Sua Majestade pretende por si só julgar da vontade da Constituição; e como eu estou altamente persuadido, que esta Assembléia se empenha em fazer uma Constituição, e portanto digna do seu monarca constitucional, proponho, que no voto de graças se declare o seguinte: - "A Assembléia se persuade não poder deixar de fazer uma Constituição digna do Imperante e do Brasil, por assim confiar nos seus sentimentos nobres e patrioticos".

Embora polida e respeitosa a Assembléia Constituinte, pela voz de um dos seus mais ilustres membros, fez chegar até o Imperador, a sua restrição aos excessos da Fala do Trono.

Àquele tempo, como ensina Homem de Melo, no Brasil,

"país fertil, cheio de elementos de riqueza, já então existia nele uma classe de proprietários abastados, que aspiravam dar. aos seus filhos uma educação mais apurada".

Desde os fins do século passado aumentaria consideràvelmente o número dos brasileiros, que foram receber instrução na metrópole, brasileiros, como os Andradas, Muniz Tavarez, Feijó, Silva Bueno, Zeferino dos Santos, Alencar, Manoel do Nascimento, Ledo, Fagundes Varela, Pires Ferreira, Martins Bastos, Araujo Lima, Fernandes Pinheiro, Lino Coutinho, Vergueiro, José Ricardo e tantos outros.

E o que se verificou, por ocasião da instalação da Assembléia Constituinte, é que dela fazia parte

"o que de mais ilustrado havia no país, tudo quanto este possuia de tradições administrativas e solicitações práticas".

A Assembléia Constituinte, logo que instalada, nomeou a comissão de deputados para elaborar o projeto da Constituição do Império do Brasil, comissão esta integrada por Antônio Carlos Ribeiro de Andrada, Antônio Luiz Pereira da Cunha, Pedro de Araujo Lima, José Ricardo da Costa Aguiar, Manoel Ferreira da Câmara Bitencourt, Francisco Muniz Tavares e José Bonifácio de Andrada e Silva. 
Na vida política brasileira estava escrito que aquela Aśsembléia Constituinte, viveiro de homens ilustres, íntegros e patriotas, não daria, ao Brasil, a sua Constituição Monárquica.

A Fala do Trono, além de motivos outros, cindira aquela unidade de vistas que, nos primeiros dias da Monarquia, ligara Pedro I aos seus cooperadores, na tarefa heróica de realizar a Independência.

Mas, durante o seu curto período de vida que foi de oito meses, a Assembléia Constituinte promulgou várias leis, dentre as quais merecem destaque: -

a). - lei determinando a legislação que vigoraria no Império após a proclamação da Independência (projeto de Ferreira da Cunha - Anais Tomo 1\%, págs. 40);

b). - lei que proibia, aos deputados, o exercício de qualquer outro emprego durante o tempo da deputação, exceto o de ministro e intendente da polícia; projeto de Araujo Viana, na sessão de 21 de julho (Anais, Tomo $2^{\circ}$, págs. 119);

c) . - lei regulando a forma que devia ser observada na promulgação dos decretos da Constituinte, sem dependência da sanção imperial; projeto da comissão de constituição, relator Araujo Lima, na sessão de 12 de junho (Anais, Tomo 2\%, págs. 61).

Outros projetos de lei mereceram a atenção dos constituintes de 1823, como os que cuidavam da extinção da escravatura, da mudança da capital do Império, da catequese e colonização dos índios, da liberdade de imprensa e da instituição do Juri.

Aqui, cumpre acentuar que o projeto de lei, regulando a liberdade de imprensa, dissolvida a Assembléia Constituinte, foi ele transformado, pelo Poder Executivo, no Decreto Imperial de 22 de novembro de 1823 .

As dissenções, entretanto, repete-se, continuariam entre a Assembléia Constituinte e o primeiro Monarca brasileiro.

Hoje, depois que os arquivos foram revolvidos mais intensamente, a partir da década de vinte, chega-se à conclusão que a vida efêmera daquela Assembléia não teve, como causas, razões apenas de ordem política. Outros motivos determinaram o violento desfecho, como as intrigas de alcova de autoria de Francisco Gomes da Silva, aquele valído da Corte mais conhecido como o Chalaça, e também, porque não dizer, o grande amor despertado, em Pedro I, por D. Domitila de 
Canto e Castro, futura Marqueza de Santos, amor este que derribou o Patriarca da Independência e que se ele, José Bonifácio, o tivesse querido, teria sido novamente reconduzido ao alto cargo de Ministro e evitado a "Noite da Agonia", aquela noite de 11 para 12 de novembro de 1823, última noite de vida da Assembléia Constituinte e, enfim, evitado a dissolução da mesma Assembléia .

$\mathrm{E}$, às treze horas daquele longínquo 12 de novembro de 1823 , o Brigadeiro José Manuel de Moraes levava à Assembléia Constituinte o decreto expedido, e datado daquele mesmo dia, do seguinte teor: -

"Havendo EU convocado, como tinha direito de convocar, a Assembléia Geral Constituinte e Legislativa, por decreto de 3 de junho do ano próximo passado, a fim de salvar o Brasıl dos perigos que lhe estavam iminentes, e havendo dita Assembléia perjurado ao tão solene juramento, que prestou à Nação de defender a integridade do Império, sua Independência. e a Minha Dinastia: Hei por bem, como Imperador e Defensor Perpétuo do Brasil, dissolver a mesma Assembléia, e convocar já uma outra na forma das Instruções feitas para a convocação desta, que agora acaba, a qual deverá trabalhar sobre o projeto da Constituição, que Eu the hei de em breve apresentar, que será duplicadamente mais liberal que o que a extinta Assembléia acabou de fazer. Os Meus Ministros e Secretarios de Estado de todas as diferentes Repartições o tenham assim entendido e façam executar, a bem da salvação do Império".

E a Assembléia Constituinte que, horas antes, se declarara em sessão permanente não se surpreendeu com o ato de força, e nem the era possível, contra o mesmo, reagir .

Lido o decreto, conservaram os Anais as últimas palavras ouvidas em plenário, partidas de Antônio Carlos: -

- Já não temos que fazer aqui... O que resta é cumprir o que Sua Majestade ordena, no decreto que se acaba de ler.

A noite daquele mesmo dia 12 de novembro de 1823, José Bonifácio de Andrada e Silva, a passaria preso, na fortaleza de Santa Cruz, onde dormiria na lage fria o seu sono, se é que dormia. Certo, entretanto, é que meditaria o velho Andrada nos acontecimentos em que, com D. Pedro e com outros ilustres brasileiros, se envolvera desde o Sete de Setembro de 1822 e, por certo também chegara à conclusão de que todos eles, inclusive o jovem monarca, estavam com o seu lugar de destaque assegurado na vida e na história política brasileira, 
como ainda concluiria que as grandes pátrias só são construidas quando tem a sua história formada por dias de paz e de lutas. 1824 .

Agora, caminhar-se-ia para a Constituição de 25 de março de

Dissolvida a Assembléia Constituinte, o Imperador, no dia 13 de novembro de 1823 , em proclamação aos brasileiros diria: -

"Continuemos a salvar o Brasil. O vosso Imperłdor e o vosso Defensor Perpétuo vos ajudará, como ontem fez, e como sempre tem feito, ainda que expondo a sua vida. Os desatinos de homens alucinados pela ambição nos iam precipitando no mais horroroso abismo. E mister, já que estamos salvos, sermos vigilantes, qual Argos. As diretrizes que devemos seguir e sustentar para a nossa felicidade são: Independência do Império, integridade do mesmo e Sistema Constitucional".

Acrecentaria ainda: -

"Está convocada a nossa Assembléia. Quanto antes ela se reunir parą trabalhar sobre um projeto de Constituição mais breve eu vo-lo apresentarei. Se possível for, eu estimo que ele vá de encontro aos vossos anseios de forma tal nos possa reger (ainda que provisoriamente) como Constituição. União e mais união, brasileiros. Confiai em mim. Eu a tenho em vós...".

O Conselho de Estado de dez membros, que teve o encargo de elaborar o ante-projeto de Constituição, mais tarde transformado na Carta Outorgada de 25 de março de 1824, foi composto pelo Professor de Retórica Mariano José Pereira da Fonseca, apelidado o "Biscoitinho", pelo habito de estar sempre a come-los, e no futuro seria ele o Marquez de Maricá; Clemente Ferreira França, Marquez de Nazaré, os quais não integravam a Assembléia Constituinte dissolvida, participando ainda do referido Conselho João Maciel da Costa, Marquez de Queluz; Carvalho e Mello, Visconde de Cachoeira; João Gomes da Silva, Marquez de Sabará; Francisco Vilela Barbosa, primeiro Marquez de Paranaguá; José Egídio Álvares de Almeida, Marquez de Santo Amaro; Antônio Luiz Pereira da Cunha, Marquez de Inhambupe; Manoel Jacinto Nogueira da Gama, Marquez de Baependi e José Joaquim Carneiro de Campos, Marquez de Caravelas. Os que cuidaram da redação da futura Constituição foram João Gomes da Silva Mendonça, Antônio Luiz Pereira da Cunha, José Egídio Álvares de Almeida, João Maciel da Costa e José Joaquim Carneiro de Campos, que tiveram franca 
colaboração do ilustre jurista Francisco Carneiro de Campos, irmão do Marquez de Caravelas, íntimo de D. Pedro e muito familiarizado com as idéia de Benjamin Constant.

Ter-se-ia a impressão, àquele tempo, de que, dado o impacto produzido na vida política e social brasileira, pela dissolução da Assembléia Constituinte, muito demoraria o Império a ter uma Constituição, tanto mais que D. Pedro, a despeito de suas tendências liberais, era oriundo de uma Corte na qual ainda preponderava o espírito do absolutismo.

Tal, entretanto, não acontecera, pois o Conselho de Estado, aqui referido, trabalhou sem descanso e, assim, já em dezembro de 1823 estava, integralmente, copiado o ante-projeto de Constituição, que iria ser submetido aos governos provinciais e às diversas Camaras Municipais.

Para o desempenho de suas relevantes tarefas o Conselho de Estado foi buscar subsídios nas

"constituições espanhola (de 1812) e portuguêsa (de 1827), muito influenciada pela Revolução de Rafael Riego, mas que a esta altura já estaria novamente sendo renegada, agora por Fernando VII na sua guerra aos "afrancesados".

\section{Também utilizou dito Conselho de Estado}

"um vasto material constante de leis inglesas, de cousas relativas ao parlamentarismo da Inglaterra também, de leis da Convenção e do período napoleônico".

Mostra Brasil Gerson, em seu recente e magnífico livro A Revolução Brasileira de Pedro I, que foi incluida no projeto da Constituição "muita coisa nova", além de

"inovações para a época, à maneira, por exemplo, dos capítulos sobre o monarca por aclamação dos povos (e não por direito divino), sobre o Poder Moderador (chave do sistema, alicerce, ou ponto de partida para o parlamentarismo do Segundo Reinado, e podendo também aqui se mencionar como inovação a criação dos Conselhos Gerais das Províncias, que alem de reforçarem o municipalismo tinham qualquer coisa de federalismo, espécie de embrião das Assembléias Legislativas que nasceriam com o Ato Adicional de 1834, e da Câmara Alta (ou Senado), com a participação do eleitorado)". 
E hoje, com o historiador acima referido, outros são concordes em admitir que a Constituição de 1824

"se caracterizava, antes de mais nada, pela sua objetividade, pela simplicidade de sua linguagem, capaz de ser entendida por uma criança, e pelo seu notável espírito de síntesc. Na verdade, reduzirá a cento e setenta e nove artigos os duzentos e setenta e dois do projeto da Constituinte, que do artigo 41 ao 147 se perdia em minucias excessivas sôbre o modo pelo qual deviam funcionar a Câmara e o Senado, matéria que melhor poderia se enquadrar no próprio Regimento Interno das duas casas. e sobre as relações entre elas e o Poder Moderador e o Executivo, e sobre o processo eleitoral a vigorar dai em diante - e sendo bom que não se esqueça também que em alguns de seus dispositivos o projeto dos conselheiros e do Imperador se mostraria mais liberal ou amplo que o dos deputados, e dessa maneira cumprindo-se, nesse particular, a promessa que ele fizera no seu decreto de dissolução de 12 de novembro".

Contem a Constituição de 25 de março de 1824 , como se referiu anteriormente, cento e setenta e nove (179) artigos, distribuidos em oito títulos que tratam: - Título I - Do Império do Brasil, do Território, Governo, Dinastia e Religião; Título II - Dos Cidadãos Brasileiros; Título III — Dos Poderes e Representação Nacional; Título IV - Do Poder Legislativo, compreendendo seis capítulos (Poder Legislativo - capítulo I; Da Câmara dos Deputados - Capítulo II; Do Senado - Capítulo III; Da proposição, discussão, sanção e promulgação das leis - Capítulo IV; Dos Conselhos Gerais das Províncias e suas atribuições - Capítulo V; Das Eleições - Capítulo VI; Título V - Do Imperador, compreendendo oito capítulos (Do Poder Moderador - Capítulo I; Do Poder Executivo - Capítulo II; Da Família Imperial e sua dotação - Capítulo III; Da Sucessão do Império - Capítulo IV; Da Regência na menoridade ou impedimento do Imperador - Capítulo V; Do Ministério - Capítulo VI; Do Conselho de Estado - Capítulo VII; Da Força Militar - Capítulo VIII; Título VI - Do Poder Judicial, com um único capítulo: - Dos Juizes e Tribunais de Justiça; Título VII - Da Administração e Economia das Províncias, compreendendo, tres capítulos (Da Administração - Capítulo I; Das Câmaras - Capítulo II - Da Fazenda Nacional - Capítulo III; Título VIII - Das disposições Gerais e Garantias dos Direitos Civis e Políticos dos Cidadãos Brasileiros.

Esta Constituição, que vigorou de 25 de março de 1824 a de novembro de 1889 , foi jurada pelo Imperador, com o preâmbulo que segue: - 
"Dom Pedro Primeiro, por graça de Deus e unanime aclamação dos povos, Imperador Constitucional e Defensor Perpétuo do Brasil:

Fazemos saber a todos os nossos súditos que, tendo-nos requerido os povos deste Império, juntos em Câmaras, que nós quanto antes jurássemos e fizéssemos jurar o projeto da Constituição, que havíamos oferecido às suas observações para serem depois presentes à nova Assembléia Constituinte, mostrando o grande desejo que tinham que ele se observasse já como Constituição do Império, por lhes merecer a mais ampla aprovação, e dele esperarem a sua individual e grande felicidade política; nós juramos o sobredito projeto para o observarmos, e fazermos observar como Constituição, que dora em diante fica sendo, deste Império; a qual é do teor seguinte:

EM NOME DA SANTISSIMA TRINDADE".

Esta Constituição foi complementada pelas seguintes leis: - Lei de $1^{\text {OO }}$ de outubro de 1828 - Criando em cada cidade e vila do Império Câmaras Municipais; Lei de 12 de outubro de 1832 - Ato de autorização para reformar a Constituição do Império; Lei de 12 de agosto de 1834 - Faz algumas alterações e adições à Constituição Política do Império nos termos da Lei de 12 de outubro de 1832; Lei $n^{\circ}$ 105 , de 12 de maio de 1840 - Interpreta alguns artigos da Reforma Constitucional; Lei $\mathbf{n}^{\circ}$ 234, de 23 de novembro de 1841 - Criando um Conselho de Estado.

Natural é que muitos, não familiarizados mais intimamente com a evolução constitucional brasileira, se admirem com o artigo 5 , da Constituição do Império, dispondo -

“A religião católica apostólica romana continuará a ser a religião do Império. Todas as outras religiões serão permitidas com o seu culto doméstico ou particular, em casas para isso destinadas, sem forma alguma exterior de templo".

José Antônio Pimenta Bueno, comentarista da Constituição do Império, mostra que

"a religião, o dever sagrado de prestar culto, de adorar o onipotente, o senhor do universo, é o primeiro e o mais justo de todos os deveres; é a lei suprema da criatura inteligente; é o seu humilde tributo ao seu criador. Esse é o princípio primordial de tôda a justiça, o primeiro fundamento de tôda a moral, e também a base das virtudes sociais". 
E como no Império, o Estado tinha a sua religião oficial, pelo artigo 93 , item $3^{\circ}$ não poderiam ser deputados os que não professassem a religião do Estado. Ainda, à vista do artigo 179 , item 50, no Império ninguém seria

"perseguido por motivo de religião, uma vez que respeite a do Estado, e não ofenda a moral pública",

o que era completado pelo artigo 191 do Código Penal que considerava crime perseguir por motivo de religião aquele que respeitara a religião do Estado, e não ofender a moral pública, crime que sujeita à pena de prisão por um a três meses, além das mais em que o delinquente possa incorrer.

A mesma Constituição apresentava uma inovação, em seu artigo 98, ao instituir o Poder Moderador, definido pelo mesmo dispositivo constitucional como a chave

"de toda a organização política, e é delegado privativamente ao Imperador, como chefe supremo da nação e seu primeiro representante, para que incessantemente vele sobre a manutenção da independência, equilíbrio e harmonia dos mais poderes políticos".

O insigne Pimenta Bueno, já citado, em seu Direito Público Brasileiro e Análise da Constituição do Império, examinando este dispositivo constitucional, acentua -

"pelo que toca à personalidade a quem deva ser confiado, não pode haver dúvida em que deve ser ao imperante, por isso mesmo que é o único poder exclusivamente próprio da coroa, independente do ministério. O depositário deste grande poder deve estar cercado de todos os respeitos, tradiçōes e esplendor, da força da opinião e do prestígio. A conciência nacional precisa crer que, superior a tôdas as paixões, a todos os interêsses, a tôda rivalidade, ninguém pode ter maior desejo e glória do que ele em que os outros poderes ativos funcionem segundo os preceitos fundamentais do Estado e façam a felicidade deste. E quem tem todos os meios de observar as suas tendências, a força necessária para reprimir as paixões, é quem está sôbre a cúpula social vigiando os destinos da nação. $O$ exercício do poder moderador é quem evita nos perigos públicos o terrível dilema da ditadura ou da revolução; todos os atributos de monarca levam suas previdentes vistas a não querer nem outra dessas fatalidades, que quase se entrelaçam e reagem".

Estas judiciosas palavras e lapidares conceitos, em relação ao Poder Moderador, instituido pela Constituição do Império, por muitos 
considerado Poder Real ou Impessoal, levam, sem que o queiramos, o nosso pensamento até aquele brasileiro impar em seu tempo, que foi Pedro II, a exercer, como se fora o fiel de uma balança, em toda a sua majestade, o Poder Moderador, no Segundo Reinado.

Hoje, e agora, podemos proclamar a nossa admiração, sempre redobrada, pelo filho do primeiro Pedro, pelo lustre que deu às funções monárquicas que exercitou por quase meio século, como pelo respeito que soube impor, às nações de todo o mundo, por este Brasil generoso e cristão.

Não é intenção minha, nesta despretenciosa palestra, uma análise demorada da Carta Outorgada de 1824.

Aqui vim para atender ao honroso convite do ilustre Presidente da Ordem dos Advogados do Brasil, na Secção do Espírito Santo Dr. Manoel Moreira Camargo - cooperar, modestamente, para esta solenidade, sentindo, entretanto, que pouco, muito pouco me foi possível trazer a tão seleto auditório.

Hoje, com o Brasil caminhando destemerosamente para o futuro que, ninguém tenha dúvida, há de the sorrir em frutos sazonados, mal não há em que se recorde, agora, as palavras extraordinárias, proferidas por José Bonifácio de Andrada e Silva, na sessão da Assembléia Constituinte, em 6 de maio de 1823:

"Queremos uma Constituição que nos dê aquela liberdade de que somos capases, aquela liberdade que faz a felicidade do estado, e não a liberdade que dura momentos; e que é sempre a causa de terríveis desordens". 